\title{
Educational Aspects of Interactive Foreign Language Learning in High Schools
}

\author{
Alexander V. Obskov \\ Svetlana I. Pozdeeva \\ Dmitry L. Matukhin
}

Gavriil A. Nizkodubov

National Research Tomsk Polytechnic University (TPU), Russian Federation, Power Engineering Institute

Emails: alexanderobskov@hotmail.com, svetapozd@mail.ru, mdlbuddy@mail.ru,mnusa@yandex.ru

\section{Doi:10.5901/mjss.2015.v6n4s3p319}

\begin{abstract}
This research was conducted to examine the main educational aspects in the organization of interactive learning at higher education systems. Today, the interactive learning is widely used in all aspects of the educational process: at colleges, at the universities, in courses and workshops, because this technique is extremely effective not only in terms of acquiring knowledge, but also by the formation of personal skills, we decided to reveal some theoretical aspects of interactive learning and its organization for teaching foreign language at high school. The use of interactive forms, methods, approaches and new information technology in the classroom for foreign language provide ample opportunity for the formation of the students the knowledge and skills that will grow into the necessary professional competence of teachers.
\end{abstract}

Keywords: the educational aspects of traditional learning; the interactive learning process; the intensification; the optimization and joint activities;

\section{Introduction}

In the present day, the communicative competency role is rising in the modern professional community. It has led to the increased importance of language training in the system of higher education. Developing international contacts and networks in different fields, the specialists are required to possess competence in at least one foreign language. It is important to note the fact of the high school students realizing the necessity of learning with the foreign language themselves. The purpose of this article is to reveal the main theoretical studies of interactive learning in the education of foreign languages, as well as its methods of providing intensification and promote business cooperation of the teacher and the student.

Recognizing the role of innovative learning technologies, we should remember that among the innovations include only those innovations, which are the embodiment of the integrated use of new methods of teaching and the rebuilding of the educational practices in order to improve its efficiency. At the present point of interactive education training, active methods are used, organizing joint ventures of the teacher and the student. In this background, the teacher is an organizer of the educational process and the student must be interested and actively participate in the learning process. This learning through exchange of information, discussion, search and discovery, solving the problem, continues to improve the teacher and the student skill as well [Obrydina 2010, pp: 32-35].

\section{Literature Review}

The research is based on the scientific papers of domestic and foreign scholars in such areas as various definitions of interactive learning, a framework for categorizing the types of instruments used to assess interactive learning style, as well as prior researches on interactive learning style. 


\subsection{Objectives of the Study}

Mastering English is an important subject matter in high schools and a lot of attempts have been made to teach this subject matter, it has not successfully been achieved. Therefore, the aim of present study is to investigate the problems of teaching and learning the English language in high schools in the field of interactive (active) teaching. Therefore, to alleviate these problems, the current investigation seeks to answer the following questions.

\section{Materials and Methods}

In recent years, the teaching of foreign languages revealed a tendency to move from the communicative approach to its varieties - the interactive one, which was proposed by Western Methodists. However, there is no clear understanding of the term "interactive approach." Usually the interactive approach to identify the communicative approach, believing that interactive model of language acquisition suggests that the learning occurs during and in the course of participation in language acts.

We examine the concept of "Interaction" (Interaction - is a kind of action that occurs as two or more objects have an effect upon one another. The idea of a two-way effect is essential in the concept of interaction, as opposed to a oneway causal effect...) which firstly was used in the social psychology. The definition of "interactive methods" consists of the definition of "method" and "interactive" (Interaction). The teaching method is understood as a way of purposeful interaction of the teacher and the student, to solve educational problems. In the concept of "interaction" can be divided into two components: the "inter"- communicate between; and "action"- educational ventures. Thus, the interaction can be understood as enhanced educational activity between anyone. On this basis, interactive methods are a targeted way to power inter-subjective interaction of the teacher and the student, to establish the optimal conditions of its development. [Beetle, \& Koshelev 2004, pp: 56, 75, 265, 56-75.]

Today, foreign language teachers of higher educational institutions are very urgent in finding new and improved methods and techniques to advance the student interests in learning the foreign language, strengthening the motivation in the learning process. One possible solution to this problem is to use interactive methods of educating the foreign language, in this case - focused on language specialties of students of higher education[Obskov 2012, pp 120-124].

At the present time, as one of the objectives is considered efficient of the educational process in each unit of time, i.e. optimal work intensification. Under the intensification we need to understand the training goal with minimum effort of the students and the teachers, taking into account indicators such as teaching quality and time saving. Its main components include: the training focusing, strengthening its motivation, the information capacity of the content of education, the use of modern teaching methods, teaching methods and activation of the pace of learning ventures, the development of labor reflective skills, computer technology use in the field of educational process and other new information of technical training.

Today the training should be built differently. It must be designed and constructed so that all the students can participate in the educational process. One of these options - the educational process with the use of interactive learning, the teacher must use the interactive learning strategies in their teaching practice. In order to effectively disclose the content of the category of "interactive learning" and its methods, we compare the traditional teaching and active interactive learning by the following limits: the goals, the position of the student and the teacher, the organization of communication in the educational learning process, teaching methods, and the principles of interactive learning.

Considering that the traditional learning methods emphasize the main goal. It is the transfer of the large volume of student's knowledge about the subject. But the main task of students is to reproduce the knowledge created by others.

Obtained competences in the traditional academic training represent a certain amount of information on various academic disciplines, which exists in the mind of the student in the form of domain- clusters do not always have a meaningful connection [Bar, \& Tag 2001, p 320]. Most of the teachers are faced with the inability to link the content of their subject knowledge with students in other subjects. Therefore, the questions arises awareness training material, and assign it to use in situations that go beyond higher education. It is difficult enough to dispel this doubt, primarily because as feedback from the student to the teacher acts as the playback process of educational material. Sh. A. Amonashvili declared: "In the past, when I was an imperative teacher, I lived with my students in creative combustion and the difficulties they faced, remained unknown to me. To them I was just a supervisor, and they are for me - rightly or wrongly solved problems "[Amonashvili 1984, p 297].

In interactive learning mastery of foreign language competence takes a different meaning. Feature of this data is that the student is not it in the form of ready-made structured system from the teacher, and in the process of its own activity. The teacher, according to $\mathrm{O}$. Bassis must create situations in which the learner is active, in which he asks', acts 
and thinks. In this sort of situations, he shared with other masters those competencies, which allows converting knowledge into what was initially a problem or obstacle.

On the other hand, a student in the process of interaction in class with other students, the teacher seizes the system tested (proven) ways of life in relation to themselves, society, the globe in general, and the various search engines acquires knowledge. Therefore, the knowledge gained by the students is a tool for self [Grigalchik, \& Hubarevich 2003].

Thus, we would like to note that the purpose of the active (interactive) learning - the teacher is to create the environment in which students themselves will be able to open, acquire and construct knowledge. This is the main fundamental difference interactive learning objectives from the traditional education system.

And then methods and techniques used in traditional teaching allow achieving in the educational process of the first three levels of objectives. In most cases, their implementation is quite a simple reproduction of its content.

Interactive teaching methods also provide the goals the first three levels, and more efficiently than traditional methods do training system. As a result, teachers working in the traditional paradigm often use interactive teaching methods for better absorption of the students' information. In this case, it will only go about optimizing the traditional educational process. This fixation is very important because it may allow the teacher to decide what sort of strategy in the plane he desires.

Continuing to analyze the purpose in the context of interactive learning, it should be noted that interactive teaching methods allow achieving in the educational process often higher order goals. At the same time, these methods contain other unit objectives, the implementation of which contributes to the development of students' social competence (the ability to lead the discussion, group work, resolve conflicts, and to listen to others, etc.) [Grigalchik, \& Hubarevich 2003, p 13-14].

In teaching literature we often find two categories: "Interactive Techniques" and "Interactive teaching Methods". The difference between these categories is the content that is embedded in the word "interactive" Saying "interactive methods", we hereby make the class focus on the interactivity of the method. The student activity in this case is secondary, i.e., stops working method - the student is no longer active. In interactive learning is the main activity of the learner, which is defined not only by itself, but also other factors such as the educational environment created in the school.

The need to focus on is that the method cannot be turned into a means of getting rid of the boredom of students in class. Created by a favorable psychological atmosphere cannot be the sole and sufficient outcome of studies. "You cannot hide incompetence in content and methodical plan, filling the educational process with a variety of methods. Even non-traditional methods cannot by themselves guarantee the success of the educational process. Only crafted and deliberate application of methods in conjunction with a thorough knowledge of the topic provides a systematic development of the educational situation".

For the process to adapt new ways of working and be successful, the student must go beyond the scope of the former "comfort zone" to expand their boundaries to feel safe in the new situation. Overcoming fear, uncertainty before the new situation, understanding and accepting the students with new requirements will in turn affect the effectiveness of its training activities.

Consider the aspect of the organization of communication in the learning process. Today the educational process as a one-way transmission of information is a form of communication that reflects the reproductive nature of learning. Its essence lies in the translation of teacher information and its subsequent playback to the student. The main source of training is the experience of the teacher. The student is in a situation where he just reads, hears, or speaks about specific areas of knowledge, taking only the position of the perceiver. Sometimes one-sidedness can be violated (for example, when a student clarifies anything or asks), and then there is a two-way communication [Obskov 2014, pp 90-93].

Characteristically, the one-sided form of communication is present not only in the lectures, but also on the seminar. The only difference is that no teacher and student broadcast some of the information. This may be the answers to the teacher question prior to the seminar questions, essays, lecture material reproduction. This form of communication that exists for so long is unacceptable today for many reasons and its criticism is becoming common place. Name just a few drawbacks to this method of teaching.

First of all the passivity of students during class, its function - hearing, while the pedagogical and sociological studies show that passive participation in the education process will be over. There is a definite pattern of learning, described by American researchers R.Karnikau and F. McElroy: people remember 10\% of reading; $20 \%$ - heard; $30 \%$ seen; $50 \%$ - seen and heard; $80 \%$ - that says it all; $90 \%$ - in order to then came in activity [Karnikau, \& McElroy. 1975].

The second reason is even more simple and obvious: one-way communication is justified only in the case of lack of information, an inability to obtain otherwise, other than as a lecturer in the story. Today, in most cases it is not. Teacher 
usually uses a material that is not original. Only original ways design, logic and manner of presentation. But it only helps the teacher: he worked appropriated knowledge, open to others. This is certainly valuable and indicates the level and skill of the teacher, but not much in the construction of knowledge contributes to a student - someone else's design knowledge never becomes. It is possible to admire, but still have to create your own.

It is a fundamentally different form of multilateral communication in the educational process. Specially organized way of multilateral communication presupposes the activity of each subject of the educational process, not just a teacher, parity, no repressive measures of management and control on his part.

It should be noted that the essence of this model of communication involves more than just tolerance utterances students, which in itself is important in bringing in the educational process of their knowledge. When students try to make their own knowledge or experience, teachers often leave it just at the level of information and do not allow happening restructuring of the subject matter, a violation of the usual communication model "opinion of the teacher - student supplement." The principles of multilateral communication, is violated, because the knowledge of student is involved only to the extent that they supplement the course of teaching. Life (or relating to the subject of study) and student experience is almost exclusively used in order to achieve a goal that (so far) is not their goal. Subject to knowledge of the student and his subjective evaluation, the expression is subject to "communicative filter" perception and understanding of the teacher [Karnikau, \& McElroy. 1975].

Today interactive learning accused in the absence of clear theoretical concepts in the mix under the same name of different approaches and methods (in particular, there is no generally accepted classification methods).

It is important to note one thing. Pedagogical practices using interactive teaching methods, note the existence of certain barriers to their use. In the article Ch.K. Bonuell and T.E. Sutherland "Continuity of active learning: choice of activities to enhance the learning of students in the audience" are the following barriers to the use of active learning [Bonuell, \& Sutherland]

- difficulty in presenting a large amount of material in the classroom ;

- active learning requires too much time to prepare for classes ;

- seems impossible to use active learning in a large audience;

- the possibility of negative consequences: the attitude of colleagues to new approaches ; impact assessment on the job teaching students; impact on the promotion.

In our opinion, these barriers need to be considered when planning your lesson and be ready to make some effort to overcome them.

The main methodological principles interactive approaches to teaching foreign languages are the following:

Mutual communication in a foreign language with a view to producing and authentic information, equally interesting for all participants in the situation, the all-important; joint activities, the interactions between three objects: the manufacturer information, recipient information and situational context; [Passow, \& Kouzovlev, \& Korostelyov 1991].

Change in the traditional role of the teacher in the learning process, the transition to a democratic style of communication; reflexivity learning, conscious and critical reflection actions, his motives, quality and results from both the teacher and students [Kashlev 2005, pp 17-43].

Thus, the efficiency of the learning process is dependent on the following principles: integrated approach to learning in the communicative situational basis; interactivity; differentiated approach; taking into account individual circumstances; variability modes; problematical (as in the organization of training materials and the learning process itself).

The principle of communicative situational training involves the use of complex communicative situations, aimed at developing the pupil's speech that promotes "overcoming a sharp transition from education to the natural conditions of communication due to the formation of students' strong associative links". At the same classes in a foreign language do not share aspects, but are complex. The principle of interactivity suggests that during the training process, students not only acquire academic and professional competence significant, but themselves change as a result of their substantive action.

The principle of an integrated approach is realized in the use of all types of speech activity (including speaking) when training translation.

Using the principle of problematical in training means that "knowledge is not being presented in a deterministic learner, finished form, intended only to remember, but given the dynamics of the transition from ignorance to knowledge, the active participation of students in obtaining part of this knowledge as a result of independent work on a solution specially selected problematic tasks". Problematical principle plays an important role in the formation of interest in the content of education and the most educational activity, which in turn increases the learning motivation and allows students to demonstrate intellectual independence and initiative. 
The principle of variability mode provides for the exchange of information on significant professional group and individual levels, as well as a combination of classroom and homework using a modern means of communication.

Combining the principle of a differentiated approach with the principle of individual characteristics, the teacher becomes free to choose a variety of instructional techniques and incentives that can maintain motivation and mental activity of students during the entire study period [Pozdeyeva 2012, pp 198-202].

Psychologists were inconclusive about the game "justifies" the transition to a new language. It is both interesting and the kind of work for the student and analogue language exercises for the teachers, to help develop the skills of all kinds of speech activity. But the new social order influenced the revision of the goals of education in general, and the English language teaching in particular. Until recently, the purpose of vocational training was to develop skills and abilities, but now popular type of person who has five competencies: social, tolerance, communicative, information.

Competence, realizing the desire to learn life.

\section{Concluding Remarks}

Surely we agree that interactive methods cannot teach in the classroom a wealth of material, with the possible exception of some embodiments of active lectures. The question arises whether it is necessary? If we adhere to the traditional values of education, then, of course, the important amount of information on the lesson, but in terms of interactive learning other more valuable - as it has been extracted knowledge of students as they use it, whether it is for them personally meaningful. After all, the information can always be found in books and on the Internet. Here the teacher is important to determine what purpose it uses active learning: students better memorize the material, but then it's an ordinary process of optimizing the traditional educational process, or it is ready for a serious and consistent change in their professional thinking and ventures, which in turn lead to changes in learning activities of students.

\section{References}

Obrydina, T. I. (2010). Formation of professional competence of future teachers in the process of learning a foreign language // Vestn. Tomsk State. ped. University (Tomsk State Pedagogical University Bulletin). № 1 (91). pp: 32-35.

Beetle, A. I., \& Koshelev, N. N. (2004). Active learning techniques in the training of teachers. Moscow: Aversev. pp: 56, 75, 265, 56-75.

Bar, R \& Tag, J. (2001). From teaching to learning - a new paradigm of higher education // University education : from effective teaching for effective learning. Sat articles, essays on didactics of higher school / Belarusian State University. Center for Development of Education . Minsk. p:320.

Amonashvili, Sh.A. (1984). Educative function evaluation teaching schoolchildren. Minsk.p: 297.

Grigalchik, E. K., \& Hubarevich, D. I. (2003). Trained differently. Active learning strategy. Minsk. p: 148.

Passow, E. I., \& Kouzovlev, V. P., \& Korostelyov, V. S. (1991). The purpose of foreign language teaching at the present stage of development of society. General methods of teaching foreign languages. Moscow.

R. Karnikau., \& F. McElroy. (1975). Communication for the Safety Professional, Chicago.

Bonuell., C. K., \& Sutherland T. I. Continuous active learning : a choice of methods to enhance the learning activities of students in a classroom // University education : from effective teaching for effective learning. Sat articles.

Kashlev., S. S., (2005). Interactive learning technology. Minsk, "Belarusian Verasen". pp. 17 - 43, 34.

Dmitry L Matukhin, \& Gavriil A Nizkodubov, \& Vadim Y Zyubanov, \& Yury R Khasanshin, \& Aleksandr V Obskov. (2014) Methodological Basics of Blended Learning in Teaching English for Academic Purposes to Engineering Students.: Asian Social Science from the following World Web Site: http://ccsenet.org/journal/index.php/ass/article/view/40783/22505

Obskov, A. V., (2014). Higher school teachers attitude to interactive foreign language teaching // Vestnik. Tomsk State. Pedagogical University (Tomsk State Pedagogical University Bulletin). № 1 (142). pp. 90-93 from the following World Web Site: http://vestnik. tspu.edu.ru/files/vestnik/PDF/articles/obskov_a._v._90_93_1_142_2014.pdf

Obskov, A. V., (2012). The Problem of Interactive Study of Teaching Foreign Language at Higher School // Vestnik. Tomsk State. Pedagogical University (Tomsk State Pedagogical University Bulletin). № 11 (126). pp. 120-124 from the following World Web Site: http://vestnik.tspu.edu.ru/files/vestnik/PDF/articles/obskov_a._v._120_124_11_126_2012.pdf

Pozdeeva, S. I., (2012). Open joint program of teacher and child: content, evidence, results // Vestnik. Tomsk State. Pedagogical University (Tomsk State Pedagogical University Bulletin). № 4 (119). pp. 198-202 from the following World Web Site: http://vestnik.tspu.edu.ru/files/vestnik/PDF/articles/pozdeeva_s.i._198_202_4_119_2012.pdf 